\title{
Exploring the Impact of Abortion on Female Students at a South African University Campus: A Phenomenological Study
}

\author{
J.G. Kheswa
}

\author{
S. Takatshana \\ Department of Psychology, University of Fort Hare, \\ Alice Campus, South Africa \\ E-mail:jkheswa@ufh.ac.za
}

Doi:10.5901/ajis.2014.v3n1p111

\begin{abstract}
It is disturbing that a significant proportion of female students at the South African universities abort. The present study sought to explore the impact of abortion on the lives of female students at tertiary institutions. Many scholars identified the following factors as primary contributory factors leading to abortion among female students; socio-economic status, poor parent - child relationship, lack of parenting skills, future academic goals, marital status, religion and/or culture. A focus group interview with six female participants (who were purposively sampled), was employed in this study. The results revealed that most participants reported negative emotions (e.g. guilt, emptiness, regret and hatred towards their parents), and cited that they had no knowledge that abortion could lead to damaging the womb or maternal death. The recommendations are that female students should be engaged in sexual behaviour discussions to enable them to make informed decisions and be equipped with coping strategies after termination of pregnancy.
\end{abstract}

Keywords: abortion/ unwanted pregnancy, female students, posttraumatic stress- disorder, stigma,

\section{Introduction}

Unwanted pregnancies and abortions have existed since time immemorial (Devereaux, 1976; Kaufman, 2004) and are subjected to stigmatization in most societies (Charles, Polis, Sridhara \& Blum, 2008). For fear of the stigma from the society, female students at tertiary institutions tend to abort or terminate unwanted pregnancies owing to so many reasons ranging from poor socio-economic conditions, rape, uncommitted sexual partners, authoritarian parents and peer influence to unpreparedness of motherhood (Ajadi, 2009). Despite that safe abortions are done in hygienic settings following legalization of Termination of Pregnancy (TOP) Act No. 92 of 1996 in South Africa (World Health Organisation, 2003), the scientific evidence shows that abortion poses significant risk to women's mental health and carries a greater risk of emotional harm than childbirth (Coleman, 2006; Cougle, Reardon \& Coleman, 2005). To this end, the Health Systems Trust, indicates that the number of pregnancy terminations in South Africa increased from 26,455 in 1997 to 53,967 in 2001, and the majority of women were reported to be still at school or universities (Cooper, Chelsea, Orner, Moodley, Harries, Cullingworth \& Hoffman, 2004). In a study conducted among 750 young women seeking TOP at Bloemfontein State- Hospital, in South Africa, Lang, Joubert and Prinsloo (2005) found that $73.3 \%$ were not using any form of contraception, despite $84.3 \%$ of them having previously received information on family planning. Abortion is defined as a miscarriage of birth especially if deliberately induced and the abortion methods include removing the content of the uterus through the vagina (surgical evacuation) and using drugs to stimulate the contractions of the uterus so that its contents are expelled especially in the first 28 weeks of human pregnancy (Althaus, 2000; Coleman, 2006; Patel \& Myeni, 2008).

In 2006, the Department of Health released shocking figures of reported 9, 895 abortions by women under age 20 in South African state hospitals as compared to 4, 423 in 2001(Ertelt, 2007). In another quantitative study by Althaus (2000), among black South Africans, 50\% of women who performed abortions was below the age of 25 and around 60\% of abortions were performed on never married women. By provinces in South Africa, research by Macleod and Tracy (2010) shows that abortion by female students in rural areas of Eastern Cape is due to the lowest condom use despite access to the clinics within the campuses. Perold, Kerr and Penaluna (2010) found that at Rhodes University in the Eastern Cape, 19 abortions were officially reported to the Health Care Centre in 2009 alone and these figures do not 
include students who opt for the backstreet abortion route making definite statistics impossible to attain (Pattinson, Snyman \& MacDonald, 2006).

When female students realize that they have been impregnated by married and/or older sexual partners who are unemployed, they are more likely to opt for abortion so that their studies do not become adversely affected (Patel \& Kooverjee, 2009). Vlassoff, Shearer, Walker and Lucas (2008) found that in families which uphold culture and religion, pressure for their pregnant daughters to abort may be high to maintain a cloak of secrecy, avoid the stigma that society attaches to abortion and demystify children out of wedlock. Mokgethi, Ehlers and Van der Merwe (2006) argue that when there is no social support for female students terminating pregnancies from higher learning institutions, their academic performance is bound to deteriorate thereby increasing female university dropouts. Several scholars documented that female students from authoritarian parents' households tend to be scared to share or discuss sexuality and/ or contraception with them (Ehlers, 2003; James, Reddy, Taylor \& Jinabhai, 2004; Patel \& Kooverjee, 2009). For fear of being punished and/or rejected, when they find themselves pregnant, they decide on performing abortions without even involving their parents (Louw \& Louw; 2007; Pastorino \& Doyle-Portillo, 2009; Vundule, Maforah, Jewkes \& Jordaan, 2001). This style eventually disrupts all aspects of development, including attachment, cognition, emotional and social skills, (Coon \& Mitterer, 2010; Louw \& Louw, 2007; Patel \& Myeni, 2008). Additionally, Sigelman and Rider (2009), advocate that this parenting style perpetuates a lack of attachment between the parents and the female students. Kalipa (2010) provides evidence in this regard. It was reported that up to 80 African females performed abortions at the Khayelitsha Youth Clinic in Cape Town. These African females revealed that they were scared of their parents and might lose all the trust they have in them. These youth reported that they chose abortion because they were driven by fear of losing their study bursary. In contrast, when female students are being well informed and supported in their choices, they may experience good psychosocial outcomes from TOP (Lazarus, \& Folkman, 1984; Lie, Robson \& May, 2008).

Female students who have had abortions suffer an increased risk of anxiety, excessive worry, nightmares, insomnia, depression, negative social relationships and suicide attempts (Bradshaw \& Slade, 2003; Noleen -Hoeksema, 2008). Emotional distress such as remorse, guilt feelings, self- condemnation, tendency to cry out without cause, discomfort upon meeting babies, or recurrent fantasizing about the baby (its gender, looks, etc) become evident (Soderberg, Janzon \& Sjoberg, 1998). It was found that female students who aborted their unintended pregnancies were 30 percent more likely to subsequently report all the symptoms of generalized anxiety disorder than those who had carried their unintended pregnancies to term (Bachiochi, 2005). Congleton and Calhoun (1993), assert that lower degree of social support, abandonment and rejection from family members further adversely affects the aborters. Similarly, Drower and Nash (1978) and Noleen -Hoeksema (2008) found that students who had abortions were more likely to be under psychiatric treatment, admitted to increased use of alcohol, tobacco, or tranquilizers, had experienced adverse personality changes, and had greater social isolation compared to their counterparts who had been refused abortion and had a variety of other pregnancy outcomes.

In a quantitative study conducted by Ajadi (2009) among the undergraduate female students at Lagos University in Nigeria, about $80 \%$ of the participants indicated that they had lost their self- esteem and seemed overwhelmed with feelings of regrets. As a result, they experienced academic failure, lack of zeal, poor interpersonal relationships and fatigue. Trybulski (2005) further goes on to say that when grief remains undiagnosed, greater are the chances of marital conflicts, problems with sexual intimacy, and difficulties in parent- child relationships.

Complications due to abortion are important direct cause of maternal deaths in South Africa. The contributory causes of deaths are most commonly septic shock, followed by renal failure, disseminated intravascular coagulation (DIC), respiratory and cardiac failure (Pattinson et al., 2006). The physical after effects of abortion can be as minor as nausea, vomiting, abdominal cramps, diarrhea, etc. or may be quiet serious for instance, a possible hemorrhage (heavy bleeding) can prove deleterious as the cervix might be damaged by the surgical instruments used (Soriano, 2008). Equally concerning, during the abortion procedure, the medical staff may mistakenly leave some parts of the fetus in the maternal body itself. This can result in infections that can cause damage to the internal organs (Mbele, Snyman, \& Pattinson, 2006). Perforation of the uterus can call for its surgical removal, which means one will not be able to conceive again (Ajadi, 2009). With every abortion undertaken, the risk of not being able to conceive rises. As such the abortion procedure is detrimental in itself. What is deleterious is the effect the medication has on the body that is used before and after the abortion. Various infections can occur, which can further damage the reproductive system, making it more difficult if not impossible to conceive (Bachiochi, 2005), and several studies in the Obstetrical and Gynecological Survey show that induced abortion also increases the risk of placenta damage by 50 percent and doubles the risk of pre-term birth in later pregnancies (Bachiochi, 2005; Mbele et al., 2006). 


\section{Conceptual Framework}

This study is underpinned by the work of Lazarus and Folkman (1984) which is derived from the psychological theories of stress and coping. Although abortion can be a way of resolving stress associated with an unwanted pregnancy among university students in order to cope with their studies, Speckhard and Rue (1995) posited that the effects of abortion may impair the social and mental functioning of women who terminated their pregnancies, and manifest mental health problems similar to those experienced by individuals suffering from posttraumatic disorder (PTSD). According to Major, Applebaum, Beckman, Dutton, Russo and West (2008), an adolescent who terminates her first pregnancy, for instance, may experience different psychological effects compared to an adult woman who terminate a pregnancy after giving birth to a number of children.

For example, teenagers who terminated their pregnancies may experience post-after-abortion syndrome (PAS), namely; frequent nightmares, outburst of grief, unhappiness and anger, insomnia, depression and flashbacks (Lazarus \& Folkman, 1984). It is against this background that this study sought to investigate the following research questions: (i) What are the causal factors that influence the decision of female students to terminate pregnancy? (ii) What are the emotional and psychological effects of abortion on female students?

\section{Research Method}

The researchers used the qualitative research design for it is explorative, descriptive and inductive in its approach. Qualitative research allows data to be collected in the form of written or spoken language and analyzed by identifying and categorizing themes (de Vos, Strydom, Fouche \& Delport, 2005). As researchers, we selected issues in depth, openness and in details to identify and attempt to understand the categories of information that will merge from the data.

\subsection{Research Population and Sample}

Given the aim of the study, the target population was the female students at the University of Fort Hare, Alice Campus in Eastern Cape Province, South Africa. It is important to note that since this study was part of research project for Psychology Honours degree, the participants who voluntarily shared their experience were known to the researcher.

The sampling technique that the researcher used was purposive sampling because in purposive sampling the researchers select only those individuals that yield the most information about the topic under investigation as suggested by Leedy and Ormrod (2005). The sample comprised six African female students, whose age ranged from 18 to 24 years and had performed abortion.

\subsection{Instruments}

Focus group interview was chosen as this method has a number of distinct advantages for the study of shared experiences and understandings. It provides a comfortable environment, which facilitates disclosure, encourages elaboration and allows for female students' impact of abortion to be explored (de Vos et al., 2005). Whilst the focus group is guided by an interview schedule of key questions, the development of the conversation is driven by the group. This frees the discussion from existing preconceptions and allows the researcher to engage with unforeseen topics that may arise during the course of the discussion (Nicolson \& Anderson, 2003).

This methodology has specific drawbacks as highlighted in Puchta and Potter's study of focus groups (Puchta \& Potter, 2002). Poorly conducted focus groups can encourage artefactual production of stand-alone opinions and bias if the researchers are unskilled (Leedy \& Ormrod, 2005). With these warnings in mind, the purpose of the focus group was threefold: to map out the terrain of female students' decisions to opt for abortions: to determine whether or not they considered the risks involved when performing abortion, and finally to examine how they cope psychologically, socially and educationally with a view to elucidate the coping strategies after abortion.

\subsection{Materials}

A semi- structured interview schedule was developed to guide the focus group discussion. The schedule consisted of a series of core questions to ensure a degree of comparability between resultant transcripts. Around this, a more flexible and open approach was taken to ensure that the moderator merely facilitated, whilst the group dictated the direction of 
the discussion. Core questions were constructed using issues highlighted in causal factors, impact of abortion on female students literature, thereby asking participants to comment upon the various factors affecting them (Bachiochi, 2005; Kalipa, 2010). The issues discussed included: reasons for abortion, the effects of abortion and recommendations to alleviate post-traumatic stress disorder associated with abortion.

\section{Trustworthiness}

In establishing the "truth value" of the research study, four alternative constructs by Guba and Lincoln (1985) were followed, namely; credibility, transferability, dependability and confirmability .

- Credibility refers to how accurately the data reflect reality (Maree, 2010). In this research study, as suggested by Creswell (2005) the researchers became involved during the focus group when the participants responded to the open-ended questionnaires in face to face interview to ensure that finding are credible.

- Generalizability: According to Maree (2010), generalizability is the extent to which generalization can be made from findings to a population. As six participants as the sample for this study were used, the sample shared the same characteristics (e.g. culture, race and language) and the sample's empirical findings could be made broader inferences.

- Confirmability: It is the degree to which others can confirm the results (Kalof, Dan \& Diets, 2008). In this research study, the researchers relied on details of the participants' response which were later coded using axial coding from grounded theory approach.

- Dependability: Dependability reflects how truthful the researcher is. It is the collection and presentation of data (Kalof et al., 2008). In this study, the researchers asked the questions which are embodied in the theory of abortion.

\section{Ethical Consideration}

Ethical principles were complied with as they served to safeguard the dignity, rights, safety and well-being of all the participants in the research study (Miller, 2007). The researchers ensured that the ethical principles met the national and international standards governing research of this nature with human participants (Leedy \& Ormrod, 2005). The Research Committee of the Faculty of Social Science and Humanities endorsed the study and informed consent was obtained from each participant prior to conducting the focus group (by signing the consent form). By informed consent, Miller (2007) states that the participants must be told prior to the research what the nature thereof will be and what the procedure will entail and furthermore they may cease participation in the study at any time without penalty as the study is voluntary. The focus group was conducted in the Psychology laboratory, in August 2010, with chairs placed in a circle in the middle of the room. A tape-recording device was placed on a small table in the middle of the circle to ensure optimal recording of the focus group interview. It was explained to the group that there would be recorded, their dignity respected and anonymity reassured. Research participants were not exposed to undue physical or psychological harm. The researcher ensured that reasonable efforts were made to minimize the discomfort and loss of self-esteem, as suggested by Miller (2007), as the study under research was sensitive. The environment was quiet and none of students or lecturers interrupted during the process of interviews. All participants were assured that data collected will be treated with confidentiality and that it will be only be used for the purpose of this study. Also, during the interview, participants were not asked to mention their names.

\section{Analysis}

The focus group was conducted by a research student as previously mentioned for ethical reasons. During discussion the interviewing moderator probed the group with questions and asked for clarification on issues to ensure an in-depth articulation of the group's views. The moderator was able to direct conversation to the less active members of the group in an attempt to span the diversity of all experiences and opinions. The discussion lasted approximately 40-50 minutes. Focus group interviews were transcribed from the tape recordings into both electronic and printed form. Each transcript was read several times before beginning the analysis, as suggested by Babbie (2008). To identify themes of this study, the researchers used the following steps as suggested by de Vos et al., (2005): open coding, axial coding and selective coding. In open coding the data was divided into segments and then scrutinized for commonalities that reflected categories or themes. After the data was categorized it was further examined for properties, specific attributes or 
subcategories that characterized each category. Secondly, axial coding was done. Axial coding entails making interconnections among the categories and subcategories (Leedy \& Ormrod, 2005). Then the researchers focused on determining more about each category in terms of:

- The conditions that gave rise to it.

- The context in which it's embedded.

- The strategies which people use to manage or carry it out.

- The consequences of those strategies.

In selective coding the categories and their interrelation were combined to form a story line that describes what happens in the phenomenon being studied. Lastly, a theory in form of verbal statements was offered to explain the phenomenon in question.

\section{Discussion of Research Findings}

The analysis resulted in the development of seven key themes:

\subsection{Financial constraints:}

Most female students decided to have an abortion because the pregnancy represents a problem in their lives. These participants expressed lack of finance. They stated that they have low or no income at all. Hence, they could not afford to have babies. Five of the participants reported that because they were still students, they were not financially stable and their partners were also not working therefore raising a baby would be impossible. For example with regard to the question "what would you say influenced you the most in your decision to opt for abortion"? One participant (aged 20) said:"I was going to have financial problems apart from the fact that I am not sure who of the two boyfriends impregnated me". Another participant (aged 18), was quoted: "I did not feel ready to be a parent both emotionally and financially. And I feared rejection from my parents, my dad would have disowned me or kill me literally if he knew that I was pregnant so that is why I decided to terminate the pregnancy".

In view of the above, there is a high level of poverty in South African, especially among black children born in rural areas (Nicholas, 2008) and according to Holborn and Eddy (2011), about 73\% of 18-35 year old South Africans live in poverty as many families do not have employment. Drawing from social exchange theory, majority of females enter into multiple sexual relationships with the hope to alleviate their socio-economic status and in the process experience challenges to negotiate safe sex (Pitso, 2013; Ziyane, \& Ehlers, 2006). Poor socio-economic status of their families being the issue for female students to decide to have an abortion, Thompson and Crase (2009) and Varga (2002), argue that abortion is largely attributable to poor communication about sexual matters between parents and their daughters. When parents display warmth, prosocial-behaviour and provide consistent supervision in their parenting styles, they are perceived to instil independence, self- esteem and self- control in their youth as compared to parents with high levels of demands yet who are unsupportive and emotionally unavailable (Aspy, Vesely, Oman, Rodine, Marshall \& McLeroy, 2007). From epidemiological stance, it is clear from this finding that when adolescent females have multiple sexual partners they are also at risk of contracting sexual transmitted infections such syphilis, gonorrhoea, including HIV/Aids because of subservience to male partners.

\subsection{Discrimination:}

In addition to financial constraints, two of the female participants (aged 19 and 21) decided to have abortion because of fear of being discriminated against by their peers and community members in villages. For example, participant (aged 19) was quoted as saying: "At our church, they have been encouraging us to remain pure (i.e.virgins), so I would be an embarrassment because my friends do not have children and at my age with a child out of wedlock it is an insult".

Participant (aged 21) responded as follows: "My friends would ask if the father of the child would marry me. Also, where I come from in our village, I would be labeled as immoral".

Dealing with the stigma and issues around parenting and meeting the demands of the university is still a challenge for pregnant female students. The consequence is that unprepared mothers get overwhelmed with their situation in school and majority fails to cope with being scorned and belittled by their peers resulting in school dropout (Chigona \& Chetty, 2008). To avoid such humiliation, female students opted for abortion. The implication of this finding is that for as long as our communities ostracize pregnant teenagers rather than equip them with sexuality education, not only back 
street- abortions will be inevitable, but suicides will be reported as well.

\subsection{Desire to continue with their studies:}

Female students reported a desire to further their studies, hence they resorted to abortion. For example, with regards to the question: "What would you say influenced you the most in your decision to opt for abortion"? One participant (aged 18) said: My studies would be affected because here at tertiary if I keep the baby, I won't have a helper to look after him/her". Another participant (aged 18), uttered the following:" I was thinking about my studies. Also, if I must raise a child, it means that I won't achieve my goal of being an educator and take responsibility to help my three younger brothers". Clearly this shows why these female students who performed abortion have chosen to do so, they have distinct future career plans and carrying out the pregnancy through term seems to be standing on their way of getting education. But the question is "Do they cope?"

\subsection{Parent involvement:}

It is very rare that young people inform their parents about their decision to terminate their pregnancy as most of the participants reported that they did not involve their parents in their decision to abort. Another example with regards to question 4 "How have you involved your parents in your decision to perform abortion"? One participant (aged 19) wrote: "My mother did not know about the pregnancy as she seemed not to care about my well-being, so I did not involve her in any way. And besides I didn't want to raise my child as a single parent like her".

Another participant (aged 24) expressed herself as follows: "I do as I wish because my mother does not care and moreover, my stepfather would have chased me away with that child"

Another participant (aged 18) who stated that her parents were involved said: "I was hiding myself that I was pregnant, but immediately when my mom found out she insisted that I terminate the pregnancy. She never asked how I felt. It was totally her own decision"

The above reports by the participants give evidence of how difficult it is for young people to be able to communicate and have a warm and healthy relationship with their parents. It therefore means that when parents are uninvolved and authoritative, adolescents (especially females) are most likely to engage in risky sexual practices and endanger their lives when faced with unplanned pregnancies. To escape the whole ordeal they opt for abortion. Holborn and Eddy (2011) documented that many South African children grow up in dysfunctional families and some are affected by poverty, while others are burdened by the effects of emotional abuse as a result of maltreatment by stepparents.

\subsection{Emotional and Psychological Effects:}

Most participants reported negative emotions (e.g. guilt, always crying, emptiness, regret and hatred). For example, with regard to question "How has the abortion affected you emotionally and psychologically?" Participant (aged 18) stated "I still feel guilty no matter how hard I try to shift the blame to my mom, but I don't think anything can take away this guilt feeling. I developed some sort of hatred towards my mother. What if I won't get pregnant should I get married". Another participant (aged 20) responded as follows: "I felt a huge emptiness in my soul and no friends, alcohol drinks, or sexual partner can satisfy". The participants' responses were characterized by emotional reactions that included sadness, crying, hopelessness, loneliness and anxiety.

Until individuals come to terms with their adversity, they generally experience grief, anxiety, inadequacy, anger, vulnerability and confusion (Ross \& Deverell, 2004). It is stated that after any abortion, it is common for women to experience depression, feelings of being 'dirty,' resentment of men, and lowered self-esteem. Most participants (i.e. the female students) reported that psychological effects such as being in a depressed mood almost every day after the abortion was evident. Furthermore, participants aged (21 and 24) stated, respectively: "I would say I was depressed, I changed totally, I just lost interest in life". "At first I could not sleep, just the thought of it kept me awake all night long. It's been a year now and it has become better, but I still feel guilty and responsible for doing it".

The above reports from these participants are in congruent with the study of Bachiochi (2005) which states that women who have had abortions suffer an increased risk depression, insomnia, sense of helplessness and despair. 


\subsection{Damage to the womb:}

Most participants stated that, they at least thought about risk of damaging the womb and the inability to conceive ever again. For example with the question, "To what extent did you consider the risks involved when performing abortion? Two female students responded with regrets: Participant (aged 21) expressed uncertainty with regard to her future prospects of being a mother again. She was quoted as saying" The first thing that came to my mind was damage to the womb and the thought of not being able to conceive again".

Participant (aged 24) expressed herself in IsiXhosa- language and quoted as saying "Nangoku ndiva ubuhlungu xa ndilala nomntu ongutata, futhi sendithanda ukopha "English translation means" Even now, everytime I engage in sexual intercourse with a man, I experience pains and I bleed thereafter"

Complications such as heavy, incessant bleeding, organ damage caused by perforated uterus, infections or even adverse reactions to anesthesia can lead to damaging the womb or maternal death (Bachiochi, 2005). Comparatively, one participant (aged 18) stated that she had no knowledge of the consequences of abortion. For example, she commented as follows :"I did not consider the damages of performing an abortion as I had little knowledge about it and my mother was the one forcing me to do it"

\subsection{Repression:}

With regard to the question: "How do you cope after abortion?" It is clear that aborters repress their feelings which may have a detrimental effect on their psychological well-being in the future. For example, the three participants responded as follows;

Participant (aged 20): "I'm good but I'm trying very hard not to think about it"

Participant (aged 21) "I'm coping well but can't stop thinking about because by now I was supposed to be a mum if I didn't decide to terminate the pregnancy. Anyway l'm coping very well l'm not regretting anything."

Participant (aged 24): "By talking about it I just offload to people and I feel much better. But I'm not over it yet I guess it will take a long time for me to forget about it, maybe never".

According to Louw and Louw (2007), repression of feelings refers to the unconscious process by which thoughts, memories or impulses are held out of the awareness and may give rise to posttraumatic stress disorder (PTSD). The implication is that though the aborters try to cope by not discussing the termination of pregnancy, they experience flashbacks and undoubtedly languish.

\section{Possible Limitations}

While this study addresses some very important questions regarding the impact of abortions on the lives of female university students, it has some limitations that should be considered. A possible limitation of this investigation is related to the narrow demographics of the sample. The participants were isiXhosa speaking female students, from rural areas of Eastern Cape, below age 24 and single. Furthermore, they all came from poor socio-economic background. Thus, it can be argued that they do not represent typical females who terminate unwanted pregnancies. Therefore, because other populations may yield different results, future research should investigate the self- esteem of female students in post abortion, and the experiences of aborters who are married.

\section{Recommendation}

The results of this study demonstrate that when female students are not engaged in discussions about contraceptives and supported by parents, abortion is likely to have adverse impact- educationally, physically and psychologically. Therefore, sexuality education should be made available early at the child's education. The government and NGOs should ensure that there are youth centers to empower young people about life-skills. From attachment and psychoanalytic theories by Bowlby and Freud respectively, when parents provide nurturance consistently towards their children, they learn to develop self-efficacy and autonomy to make informed decisions regarding their sexuality as opposed to being neurotic and self-destructive owing to poor communication that prevails in the family. Finally, since the empirical findings revealed that the participants experienced anxiety and PTSD, there must be debriefing sessions for female students who performed abortion so that they could be able to cope with their studies. 


\section{Acknowledgement}

This research was financially supported by Govan Mbeki Research and Development Centre and the Department of Psychology, University of Fort Hare. We also like to extend our gratitude to female students who took part in this research.

\section{References}

Ajadi, A.O. (2009). Causes and consequences of induced abortion among university undergraduates in Nigeria. [Published Doctoral thesis]. Lagos: Lagos State University.

Althaus, F. A. (2000). Work in progress: The expansion of access to abortion services in South Africa following legalization. International Family Planning Perspectives, 26(2), 84-86.

Arthur, J. 1997. Psychological After-effects of Abortion: the Rest of the Story, the Humanist. Vol. 57, No. 2, March/April

Arthur, J. (2001). Religion and Abortion. [On-line] Available http:// mypage.direct.ac/w/writer/ Retrieved 27 July 2010.

Aspy, C.B., Vesely,S. K., Oman, R.F., Rodine, S., Marshall, L., \& McLeroy, K. (2007). Parental communication and youth sexual behaviour. Journal of Adolescence, $\mathrm{Vol}(30)$, 449-466

Babbie, E (2008). Introduction to social research. (5 $5^{\text {th }}$ edition). Wadsworth Cencage learning: Australia

Bachiochi E. (2005) "How Abortion Hurts Women: The Hard Proof." Crisis 23, no. 6 [On-line] Available: http://erika.bachiochi.com/ Retrieved 04 August 2010.

Bradshaw, Z., \& Slade, P. (2003). The effects of induced abortion on emotional experiences and relationships: A critical review of literature. Clinical Psychology Review, 23, 929-958.

Charles, V. E., Polis, C. B., Sridhara, S. K., \& Blum, R. W. (2008). Abortion and long-term mental health outcomes: a systematic review of the evidence. Contraception, 78(6), 436-450.

Chigona, A., \& Chetty, R. (2008). SA Journal of Education, Vol 28, No 2 (2008). SA Journal of Education, 28(2).

Coleman, P. K. (2006). Resolution of unwanted pregnancy during adolescence through abortion versus childbirth: Individual and family predictors and psychological consequences. Journal of Youth and Adolescence, 35(6), 903-911.

Congleton, G. K. \& Calhoun, L.G. (1993)."Post-Abortion Perceptions: A Comparison of Self-Identified Distressed and Non- Distressed Populations. The Intl J. Social Psychiatry 39(4): 255-265,

Cooper, D., Chelsea, M., Orner, P., Moodley, J., Harries, J., Cullingworth, L., \& Hoffman, M. (2004). Ten years of democracy in South Africa: Documenting transformation in reproductive health policy and status. Reproductive Health Matters, 12(24), 70-85.

Creswell J.W. (2005). Educational research. Planning, conducting and evaluating quantitative and qualitative research. (2 ${ }^{\text {nd }}$ edition). Upper Saddle River, New Jersey: Pearson Prentice Hall

Cougle, J. R., Reardon, D. C., \& Coleman, P. K. (2005). Generalized anxiety following unintended pregnancies resolved through childbirth and abortion: a cohort study of the 1995 National Survey of Family Growth. Journal of Anxiety Disorders, 19(1), 137142.

de Vos A.S, Delport C.S.L, Fouche, C.B, \& Strydom H. (2005) Research at Grass roots: For Social Science and Human Service professions. (3rd edition). Pretoria: Van Schaik Publishers.

Devereaux, G. (1976). A Study of Abortion in Primitive Societies: A Typo- logical, Distributional, and Dynamic Analysis of the Prevention of Birth in 400 Preindustrial Societies. New York:

Drower, S.J \& Nash, E.S. (1978). Therapeutic Abortion on Psychiatric Grounds. South Africa Medical Journal 54:604-608.

Ehlers, V.J. (2003). Adolescent mothers' knowledge and perceptions of contraceptives in Tshwane, South Africa. Health $S A$ Gesondheid, Vol 8, No.1: 13-25.

Ertelt, S. (2007). South Africa Abortions on the Rise, Number on Teenagers Has Doubled. [Online] Available: http://www.lifenews.com/nat3336.html Retrieved 04 August 2010.

Guba, E.G. \& Lincoln, Y.S (1985). Judging the Quality of Fourth Generation Evaluation. Newbury Park CA : Sage Publishers.

Holborn, L., \& Eddy, G. (2011). First steps to healing the South African Family. South African Institute of Race Relations: Richmond.

James, S., Reddy, S.P., Taylor, M \& Jinabhai, C.C. (2004). Young people, HIVIAIDS/STIS and sexuality in South Africa: the between awareness and behavior. Acta Paediaty, 93 (2):264-269.

Kalipa, S. (2010) West ape News: 20 Abortions a week at Khayelitsha clinic. News Agency, Cape Town, South Africa.

Kalof, L., Dan, A., \& Diets, T. (2008). Essentials of social research. Open University Press: England.

Kaufman M, (2004). Abortion and rape. [On-line] Available http://www.boundless.org/ .a0000848.html Retrieved 17 August 2010

Lazarus, R.S. \& Folkman, (1984). Stress appraisal and coping. New York: Springer.

Lang, F., Joubert, G., \& Prinsloo, E. A. M. (2005). Is pregnancy termination being used as a family planning method in the Free State? South African Family Practice, 47(5).

Lee, E. Clement, S. Ingham, R. \& Stone, N. (2004). A matter of choice: Explaining National Variation in teenage abortion and motherhood. Joseph Foundation: New York.

Leedy, P.D., \& Ormord, J.E. (2005). Practical research: planning and design. (8th edition.). Pearson Merrill Prentice Hall: Upper Saddle River, New Jersey

Lie, M.L.S., Robson, S.C., \& May, C.R. (2008). Experience of abortion: A narrative review of qualities studies. BMC Health Services 
Research, Vol 8, 150-159.

Louw, D. \& Louw, A. (2007). Child and Adolescent Development. Bloemfontein: University of the Free- State.

Macleod, C. I. \& Tracy, T. (2010). A decade later: follow-up review of South African research on the consequences of and contributory factors in teen-aged pregnancy. South African Journal of Psychology, 40 (1), 18-31.

Major, B., Appelbaum, M., Beckman, L., Dutton, M. A., Russo, N. F., \& West, C. (2008). Report of the APA task force on mental health and abortion.

Maree, K. (2010). First steps in research. Pretoria: Van Schaik Publishers.

Mbele, A. M., Snyman, L., \& Pattinson, R. C. (2006). Impact of the Choice on Termination of Pregnancy Act on maternal morbidity and mortality in the west of Pretoria: original article.

Miller, S.A. (2007). Development research methods. (3rd edition). Sage Publishers: London.

Mokgethi, N. E., Ehlers, V. J., \& Van der Merwe, M. M. (2006). Professional nurses' attitudes towards providing termination of pregnancy services in a tertiary hospital in the North West province of South Africa. Curationis, 29(1), 32-39.

Nicholas, L. (2008). Introduction to Psychology. (2nd edition). UCT Press: Cape Town.

Nicolson, P., \& Anderson, P. (2003). Quality of life, distress and self-esteem: A focus group study of people with chronic bronchitis. British Journal Of Health Psychology, 8, 251-270.

Noleen- Hoeksema, S. (2008). Abnormal Psychology. Media \& Research Update. (4th edition.). McGram- Hill Higher Education: Boston.

Pastorino, E., \& Doyle-Portillo, S. (2009). What is Psychology? International Edition. (2 ${ }^{\text {nd }}$ edition.).Wadsworth Cengage Learning: Belmont.

Patel C.J. \& Kooverjee T. (2009 ). Abortion and contraception: attitudes of South African university students. Health Care Women International; 30(6):550-68.

Patel C. J. \& Myeni M.C. Attitudes toward abortion in a sample of South African female University Students. Journal of Applied Social Psychology, 38, (3): 736-750.

Pattinson, R.C., Snyman, L.C. \& Mac Donald, A. P. (2006). Evaluation of a strict control approach in managing women with severe diseases due to abortion. SAMJ, Vol 96(11), 1191- 1195.

Perold, A. Kerr, T. \& Penaluna, J. (2010). Student abortion on the rise. www.upiu.com/

Pitso, J.T. (2013). Pregnant Teenagers Readiness For Motherhood: A Quantitative Investigation In Nkonkobe Municipality, Eastern Cape. [M.Soc. Sc Thesis]. University of Fort Hare: Alice.

Puchta, C., \& Potter, J. (2002). Manufacturing individual opinions: Market research focus groups and the discursive psychology of evaluation. British Journal of Social Psychology,41,343-363.

Ross, E. \& Deverell, A. (2004). Psychosocial approaches to health, illnesses and disabilities. Pretoria: Van Schaik Publishers.

Sigelman, C.K. \& Rider, E.A (2009) Life-span Human Development. (6 $6^{\text {th }}$ edition).Australia: Wadsworth Cengage Learning.

Soderberg, H., Janzon, L., \& Sjoberg, N. (1998). Emotional distress following induced abortion. A study of its incidence and determinants among abortees in Malmo, Sweden. European Journal of Obstetrics \& Reproductive Biology, Vol 79 (2), 173-178.

Soriano, Z.D.T. (2008). Backstreet Abortion and the WGNRR agenda [On-line] Available: http://www.isiswomen.org/index.php Retrieved 27 July 2010

Strauss, A. \& Corbin, J. (1998). Basic of qualitative research: techniques and procedures for developing grounded theory. (2nd edition). Thousand Oaks, CA: Sage

Thompson, S.D. \& Crase, S. J. (2004). Fathers of infants born to adolescent mothers: a comparison with non-parenting male peers and adolescent mothers. Children and Youth Service Review, Volume 26:489-505.

Trybulski, J. (2005). The Long- Term Phenomena of Women's Post - abortion Experiences. Western Journal of Nursing Research, Vol 27(5), 559- 576.

Varga, C. A. (2002) Pregnancy termination among South African adolescents. Studies in Family Planning, 33, 283-298

Vlassoff, M., Shearer, J., Walker, D., \& Lucas, H. (2008). Economic impact of unsafe abortion-related morbidity and mortality: evidence and estimation challenge. Vol. 59. Institute of Development Studies.

Vundule, C., Maforah, F., Jewkes, R., \& Jordaan, E. (2001). Risk factors for teenage pregnancy among sexually active black adolescents in Cape Town. South African Medical Journal,91,73-80.

World Health Organization. Reproductive Health. (2003). Managing complications in pregnancy and childbirth: a guide for midwives and doctors. World Health Organization.

Ziyane, I.S. \& Ehlers, V.J. (2006). Swazi youth attitudes and perceptions concerning adolescent pregnancies and contraception. Health S.A. Gesondheid, 11(1):31-42. 
